\title{
Home respiratory muscle training in patients with chronic obstructive pulmonary disease
}

\author{
Elvia BATTAGLIA, ${ }^{1}$ Alessandro FUlGENZI, ${ }^{2}$ Stefano BERNUCCI,${ }^{2}$ Mario E. GIARDINI ${ }^{3}$ AND \\ Maria E. FERRERO ${ }^{2}$
${ }^{1}$ Pulmonary Department, San Carlo Borromeo Hospital, ${ }^{2}$ Department of Pathology, University of Milan, and ${ }^{3}$ National Institute Physic of Matter (INFM), Segrate, Milan, Italy

\begin{abstract}
Objective and background: The benefits of inspiratory muscle strength training in decreasing symptoms, disability or handicap of patients affected by COPD are not well established. The objective of this study was to assess the efficacy of the constant use of a new flow-volumetric inspiratory exerciser, named Respivol ${ }^{\mathrm{TM}}$, in improving respiratory functional parameters in COPD patients.

Methods: Twenty consecutive ambulatory patients affected by COPD were enrolled. Each patient was assessed, before and after 3 and 6 months inspiratory exercise with Respivol ${ }^{\mathrm{TM}}$, for the following clinical parameters: maximal inspiratory pressure, maximal expiratory pressure, dyspnoea grade, quality of life by a self-administered St George questionnaire and a 6-min walking test. After a brief progressive ambulatory training programme, inspiratory exercise with Respivol ${ }^{\mathrm{TM}}$ was performed at home for 6 months. All patients used Respivol ${ }^{\mathrm{TM}}$ together with medical treatment.

Results: Maximal inspiratory pressure and maximal expiratory pressure values were significantly increased after 3 and 6 months of exercise. Dyspnoea grade was significantly reduced and the 6-min walking test showed an increase in effort tolerance, after 6 months of home training. Quality of life assessment showed an improvement, associated with a decrease of respiratory disease symptoms. Conclusions: Inspiratory muscle strength training with Respivol ${ }^{\mathrm{TM}}$ seems to be efficient in reducing symptoms and improving quality of life in adults with COPD.
\end{abstract}

Key words: COPD, inspiratory muscle training, pulmonary rehabilitation.

\section{INTRODUCTION}

Pulmonary rehabilitation for patients affected by chronic lung disease is accepted as a useful treatment option to reduce symptoms and improve functional ability as well as quality of life (QoL). In particular, patients affected by COPD frequently use health-care resources to improve lung performance. The first goal

Correspondence: Maria Elena Ferrero, Istituto Patologia Generale Via Mangiagalli 31, 20133 Milano, Italy. Email: mariaelena.ferrero@unimi.it

Conflict of interest: The authors have declared they do not have any financial or other affiliation with RespivolTM, who developed and sells the product that they tested. of rehabilitation is to restore patients to the highest possible level of independent function, in order to increase their level of pulmonary activity through exercise training and to reduce and gain control of symptoms. ${ }^{1,2}$

Inspiratory muscle activity may be compromised in patients with COPD: such impairment may contribute to dyspnoea, ${ }^{3}$ exercise limitation ${ }^{4}$ and hypercapnia. ${ }^{5}$ The rationale for ventilatory muscle training is that the enhancement of respiratory muscle function potentially reduces the severity of breathlessness and improves exercise tolerance. ${ }^{1}$

Respiratory muscle strength is routinely estimated by measuring the maximum negative inspiratory pressure generated against an occluded airway (PImax), ${ }^{6}$ although this is a highly effort-dependent test. Inspiratory muscle training (IMT) is generally initiated at low intensities and then gradually increased to achieved $60-70 \%$ of PImax. The minimal load required to achieve a training effect is $30 \%$ of the PImax.

This is the peer reviewed version of the following article: BATTAGLIA, E., FULGENZI, A., BERNUCCI, S., GIARDINI, M. E. and FERRERO, M. E. (2006), Home respiratory muscle training in patients with chronic obstructive pulmonary disease. Respirology, 11: 799-804. doi: 10.1111/j.1440-1843.2006.00951.x DOI :10.1002/jbio.201300034, which has been published in final form at http://onlinelibrary.wiley.com/doi/10.1111/j.1440-1843.2006.00951.x/abstract . This article may be used for non-commercial purposes in accordance with Wiley Terms and Conditions for Self-Archiving 
Two methods of IMT most often used are threshold loading and resistive loading. By using threshold loading, the training load is independent of flow, ${ }^{8,9}$ and requires the build-up of negative pressure before flow occurs, so resulting inertive in nature. Inspiratory resistive loading has been recently shown to be able to attenuate the heart rate, the ventilatory and perceptual response to constant workload exercise and to improve the cycling time to exhaustion. ${ }^{10}$ Threshold and resistive training effects have not been adequately compared. In addition, although IMT using adequate loads improves strength of the inspiratory muscles in patients with $\mathrm{COPD},{ }^{11,12}$ it remains unclear whether this training influences the decrease in symptoms, disability or handicap that occurs.

Even if the benefits of inspiratory muscle strength training are not well established, ${ }^{13}$ there is some evidence that improvement in inspiratory muscle strength in COPD is accompanied by decreased breathlessness and increased respiratory muscle endurance (maximum pressure generated against a progressive increasing inspiratory threshold load). ${ }^{14,15}$ Further research is needed to identify both ideal candidates and the diseases that are suitable for IMT, and to clarify its efficacy and role in pulmonary rehabilitation programmes.

The aim of this study was to verify the utility of using a new flow-volumetric inspiratory exerciser to improve respiratory functional parameters in COPD patients.

\section{METHODS}

Respivol $^{\mathrm{TM}}$ (Medinet, Milano, Italy) is a disposable (single-patient, rather than single-use) device specifically designed for inspiratory exercise (Fig. 1). It allows a real-time evaluation of inspiratory flow and volume of the patient. It consists of a piston-like

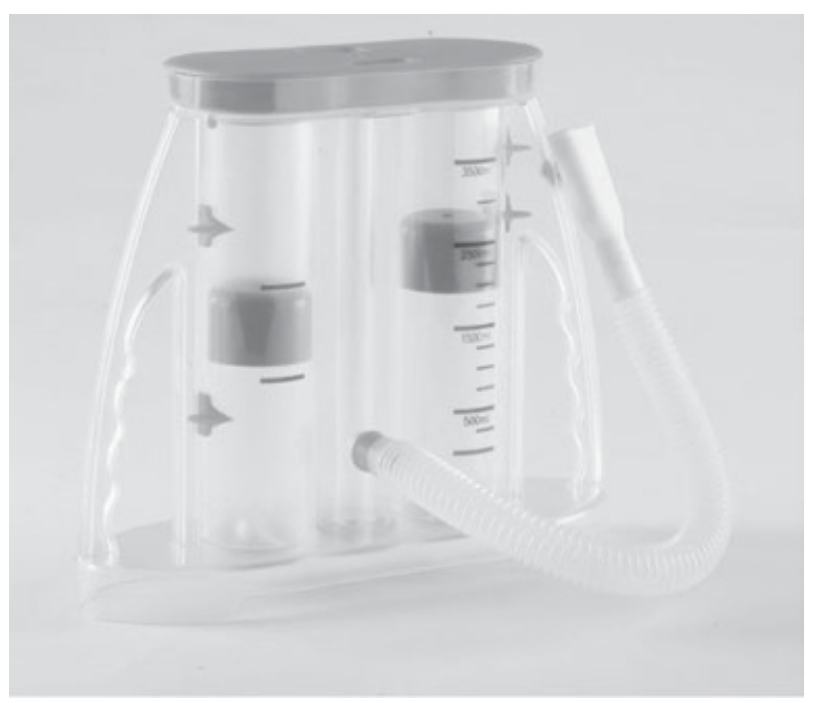

Figure 1 The device Respivol ${ }^{\mathrm{TM}}$ is depicted. chamber, containing a mobile indicator (or 'float') for the evaluation of the total inspiratory volume, and a conical flow-meter chamber, again with a float, that indicates to the patients when the flow is adequate both for the exercise, and for a correct readout of the volume. The chambers are connected between themselves and to the patient by a mouthpiece tube and by dismountable filters at the base of each chamber. Unlike similar devices present on the market and employed for the inspiratory flow measures, it does not rely upon calibrated friction between the floats and the respective chamber, thus being quite immune to decalibration problems. Moreover, an adequate hydrodynamic damping of the floats permits a natural and progressive inspiration. More precisely, because the Respivol ${ }^{\mathrm{TM}}$ chambers are not airtight and a little loss of air between chamber and float is possible, the instrument remains stable even if the chamber is contaminated by dust particles. In addition, the float is heavy with respect to that of other commercial breath incentivators, thus allowing the patient to have a slower reaction time and to delay the shortness of breath.

Exercise protocols were based upon the fact that movement of the floats during each inspiration allowed an instantaneous assessment of inspiratory flow (volume/time) and of total inspiratory volume, reported in millilitre (maximal value $=3500 \mathrm{~mL}$ ). The value of such assessment is visually indicated by the height reached by floats in the chambers. The patients, if properly instructed, can learn to consider the height as a target performance, or 'goal', that can be set by the physician by moving mobile and specifically provided indicators present on the chamber walls. Alternatively, they can write on the external surface of the device, as an apposite treatment of such surface permits the use of an ordinary pen or pencil. The patients can thus intuitively see, both during the exercise and as subsequent exercises are performed, whether the target is being reached.

Investigations were performed following approval of the institutional committee on human experimentation and all patients signed an informed consent. IMT was performed at the patient's home as a prospective study. Twenty (12 men, mean age 66.4 years) consecutive ambulatory COPD patients were enrolled. The diagnosis of COPD was made as previously reported ${ }^{16}$ as was based upon the functional obstruction criteria as described in the GOLD guidelines on spirometry $\left(\mathrm{FEV}_{1} / \mathrm{FVC}<70 \%\right)$. In order to avoid the inclusion of patients with asthma, a diagnosis of COPD was reserved for subjects with negative bronchodilator test or, in the case of a positive bronchodilator test, values after the challenge still had to fulfil the criteria for bronchial obstruction. GOLD criteria were also followed for staging COPD severity into mild $\left(\mathrm{FEV}_{1}>80 \%\right)$ (Stage $\left.\mathrm{I}\right)$, moderate $\left(\mathrm{FEV}_{1}\right.$ between $50 \%$ and $80 \%$ ) (Stage II), severe $\left(\mathrm{FEV}_{1}\right.$ between $50 \%$ and 30\%) (Stage III) and very severe $\left(\mathrm{FEV}_{1}<30 \%\right)$ (Stage IV). ${ }^{16}$ Nine patients were affected by cardiac disease (hypertension, ischarmic heart disease, arrhythmia and valvulopathy); and two patients had two different associated heart disorders. All the patients were given medical inhaled therapy for 
COPD: 11 patients received fluticasone propionate $(250 \mu \mathrm{g} \times 2$ /day $)$ and salmeterol xinafoate $(50 \mu \mathrm{g} \times 2$ / day); four received ipratropium bromide $(200 \mu \mathrm{g} \times 2$ / day) and fluticasone propionate $(250 \mu \mathrm{g} \times 2 /$ day $)$; five received fluticasone propionate $(250 \mu \mathrm{g} \times 2 /$ day $)$ plus salmeterol xinafoate $(50 \mu \mathrm{g} \times 2$ /day $)$ plus ipratropium bromide $(200 \mu \mathrm{g} \times 2$ /day $)$.

Each patient was evaluated on three occasions: the first visit was at time 0 , for example before the use of the inspiratory exerciser, the second after 3 months and the third after 6 months from the beginning of exerciser use. During these visits the patients had to perform spirometry, by which $\mathrm{FEV}_{1}$, $\mathrm{VC}$ and $\mathrm{FEV}_{1} / \mathrm{VC}$ ratio, maximal inspiratory pressure (MIP) and maximal expiratory pressure (MEP) were measured (Sensor Medics; Vmax 22, Yorbalinda, CA, USA); a pulse oximetry (Pulsox-3iA, Konica-Minolta, Osaka, Japan); an evaluation of heart rate and of dyspnoea grade by modified Borg scale and MRC (Medical Research Council) scale. The patients then performed an evaluation of QoL by a self-administered St George questionnaire and a 6-min walking distance (6MWD) test, at time 0 and after 6 months. The dyspnoea grade and the heart rate were measured when the patients were at rest.

During the first visit each patient received the new flow-volumetric inspiratory exerciser (Respivol ${ }^{\mathrm{TM}}$ ), and received a brief ambulatorial training until achieving $45 \mathrm{~min}$ of exercise per day. The patients were also instructed to use Respivol ${ }^{\mathrm{TM}}$ after the training period. The patients were invited to breathe to the maximum level of their ability in order to reach their maximum inspiratory volume (without hyperventilation, in order to avoid respiratory alkalosis) for the maximum possible time (so the respiratory frequency was determined for each patient by observing the value of maximum inspiratory volume reported on the Respivol ${ }^{\mathrm{TM}}$ chamber). The observations were performed daily to evaluate any increase of the maximum inspiratory volume. The device was used by all patients at home on a daily basis for 6 months, three times a day for $15 \mathrm{~min}$.

The ventilatory variables, for example tidal volume and breathing frequency, were recorded for each patient by spirometry before the use of Respivol ${ }^{\mathrm{TM}}$ and at each programmed visit. The compliance of the daily use of the Respivol ${ }^{\mathrm{TM}}$ was encouraged over the phone by calling the patients once a week. The patients were visited at the hospital.

\section{Statistical analysis}

One-way anova was used and significance was assumed when $P<0.05$. Data are shown as mean \pm SEM.

\section{RESULTS}

The values (in millilitre) reached during the inspiratory exercise and read on the scale in the right Respivol $^{\mathrm{TM}}$ chamber (see Fig. 1) were different for

each patient before the beginning of IMT. These
Table 1 Characteristics of the enrolled patients

\begin{tabular}{lc}
\hline Parameters & \\
\hline Mean age (years) & $66.40 \pm 0.50$ \\
Gender (male/female) & $12 / 8$ \\
$\mathrm{FEV}_{1}(\mathrm{~L})$ & $1.38 \pm 0.14$ \\
$\mathrm{FEV}_{1}(\%)$ & $55.65 \pm 4.12$ \\
$\mathrm{FVC}^{(\mathrm{L})}$ & $2.33 \pm 0.16$ \\
$\mathrm{FEV}_{1} / \mathrm{FVC}(\%)$ & $57.77 \pm 2.82$ \\
Duration of COPD (years) & $15.40 \pm 0.80$ \\
Stage of COPD & \\
$\quad$ Stage I (mild) & 3 \\
Stage II (moderate) & 10 \\
Stage III (severe) & 5 \\
Stage IV (very severe) & 2 \\
Comorbidity & 11 \\
\hline
\end{tabular}

values increased in all patients after 6 months IMT by $20 \% \pm 2$. Table 1 reports the characteristics of the patients recruited for the study.

\section{Effect of RespivolTM on lung functional parameters}

The target reached by the patients before the training was $1300+200 \mathrm{~mL}$; it increased to $2000+150 \mathrm{~mL}$ after 3 months and to $2400+250 \mathrm{~mL}$ after 6 months. Lung functions, expressed as $\mathrm{FEV}_{1}, \mathrm{VC}, \mathrm{FEV}_{1} / \mathrm{VC}$, MIP and MEP, measured before Respivol ${ }^{\mathrm{TM}}$ use (basal values) and after 3 and 6 months of home respiratory muscle training are reported in Figure 2.

The functional parameters $\mathrm{FEV}_{1}, \mathrm{VC}$ and $\mathrm{FEV}_{1} / \mathrm{VC}$ did not significantly vary following 3 and 6 months of home respiratory muscle training (Fig. 2a). FEV 1 was $1.31 \pm 0.17$ at 3 months and $1.36 \pm 0.18$ at 6 months versus basal values of $1.24 \pm 0.17(P>0.05)$. VC was $2.24 \pm 0.21$ at 3 months and $2.24 \pm 0.18$ at 6 months versus basal values of $2.14 \pm 0.19(P>0.05)$. Noteworthy, the MIP and MEP values significantly increased after 3 and 6 months of exercise (Fig. 2b). MIP was $50.78 \pm 5.28$ at 3 months and $58.61 \pm 4.43$ at 6 months versus basal values of $41.22 \pm 3.78(P<0.05)$. MEP was $70.06 \pm 3.87$ at 3 months and $77.50 \pm 4.29$ at 6 months versus basal values of $59.00 \pm 4.53(P<0.05)$.

\section{Effect of Respivol ${ }^{\mathrm{TM}}$ use on dyspnoea}

Dyspnoea grade at rest was evaluated, as reported in Figure 3, by Borg scale (a) and by MRC scale (b), before the use of RespivolTM (basal values) and 6 months after home exercise with Respivol ${ }^{\mathrm{TM}}$. Dyspnoea grade was significantly reduced after 6 months of home respiratory muscle training with Respivol ${ }^{\mathrm{TM}}$.

\section{Influence of Respivol ${ }^{\mathrm{TM}}$ use on QoL}

The evaluation of QoL, through the St George respiratory questionnaire showed that the use of Respivol ${ }^{\mathrm{TM}}$ 
(a)

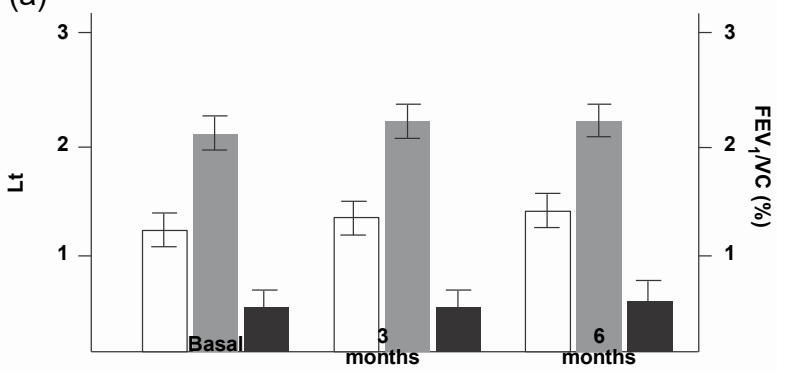

(b)

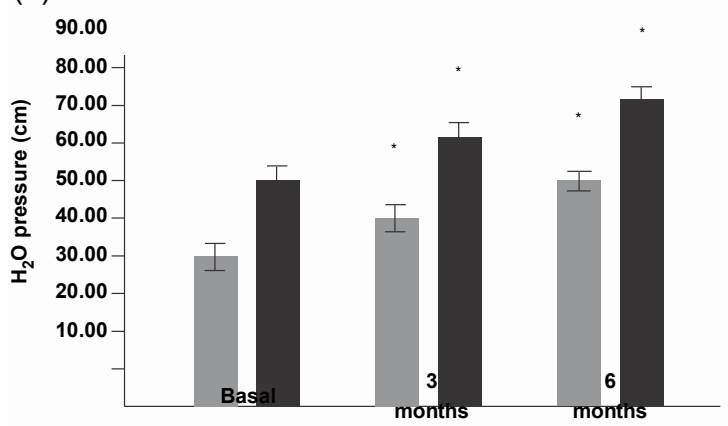

Figure 2 (a) $\mathrm{FEV}_{1}, \mathrm{VC}$ and $\mathrm{FEV}_{1} / \mathrm{VC}$ ratio, expressed in litres (Lt) and mean \pm SEM of 20 values, are reported. ( ) $\mathrm{FEV}_{1},(\square) \mathrm{VC}$, ( ) $\mathrm{FEV}_{1} / \mathrm{VC}$. (b) Maximal inspiratory $(\square)$ and expiratory pressure ( ), expressed in $\mathrm{cm} \mathrm{H}_{2} \mathrm{O}$ and mean \pm SEM of 20 values, are reported. ${ }^{*} P<0.05$ versus basal values.

for 6 months induced a significant improvement in the QoL (e.g. reduced limitation of physiological daily activities, and reduction of negative life impact associated with a decrease in respiratory symptoms), as shown in Figure 4. More precisely, (i) the respiratory symptoms were $30.19 \pm 4.93$ at 6 months versus basal values of $43.57 \pm 6.00(P<0.05)$; (ii) the physiological daily activity limitation was $45.96 \pm 4.22$ at 6 months versus basal values of $52.99 \pm 5.10(P<0.05)$; (iii) the negative life impact was $17.24 \pm 3.01$ at 6 months versus basal values of $25.76 \pm 4.49(P<0.05)$; and (iv) total parameters were $28.08 \pm 3.36$ at 6 months versus values of $36.97 \pm 4.55(P<0.05)$.

\section{Influence of Respivol ${ }^{\mathrm{TM}}$ use on $6 \mathrm{MWD}$ test}

The 6MWD test evaluation showed an increase in effort tolerance by COPD patients, following 6 months of exercise with Respivol ${ }^{\mathrm{TM}}$, compared with basal values obtained before the training with Respivol $^{\mathrm{TM}}$. In fact, there was a significant increase in the walking distance performed by patients. We separately considered the results obtained in female and male exercise, ${ }^{17}$ as reported in Figure 5. Noteworthy was the increase in effort tolerance due to Respivol $^{\mathrm{TM}}$ use was evident both in female and in (a)

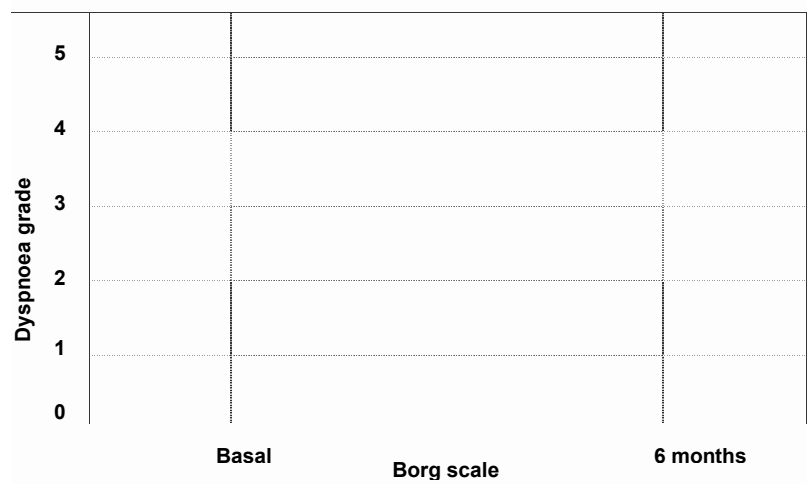

(b)

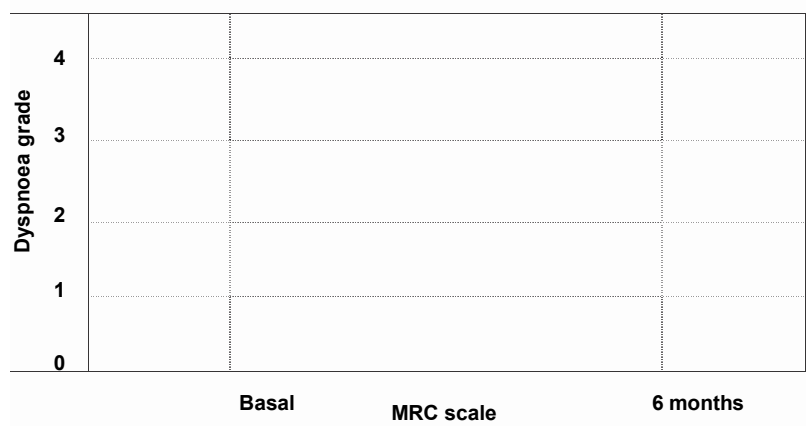

Figure 3 Dyspnoea grade at rest, evaluated by the use of (a) modified Borg scale and of (b) MRC (Medical Research Council) scale, and performed on 20 patients, before home use of Respivol ${ }^{\mathrm{TM}}$ (basal values) and after 6 months of maximal inspiratory pressure with Respivol ${ }^{\mathrm{TM}}$. Grade $0=$ absent; grade $1=$ very-very low; grade $2=$ very low; $3=$ low; $4=$ moderate $5=$ severe.

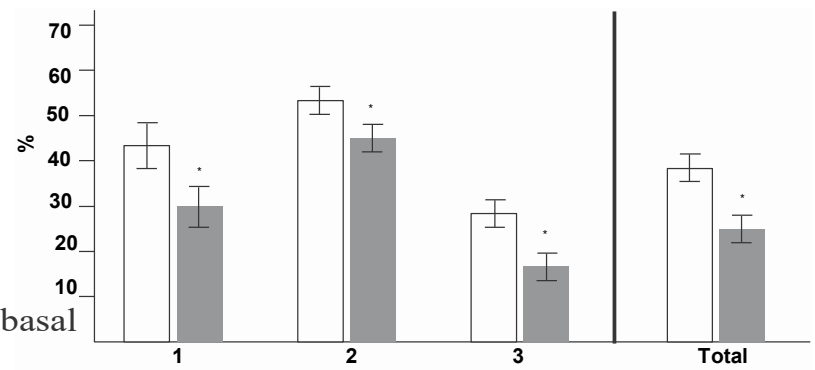

Figure 4 The quality of life parameters, as measured by the St George questionnaire, and measured before the use of Respivol $^{\mathrm{TM}}$ (basal, ) and after 6 months from its use ( $\square$ ), expressed in per cent, represent the mean \pm SEM of 20 values. 1 = respiratory symptoms; 2 =physiological daily activity limitation; $3=$ negative life impact. $* P<0.05$ versus basal values.

male patients

\section{Influence of RespivolTM use on dyspnoea at the end of a 6MWD test}

A reduction in dyspnoea grade perceived by patients at the end of a 6MWD test was noted after 6 months of 
(a)

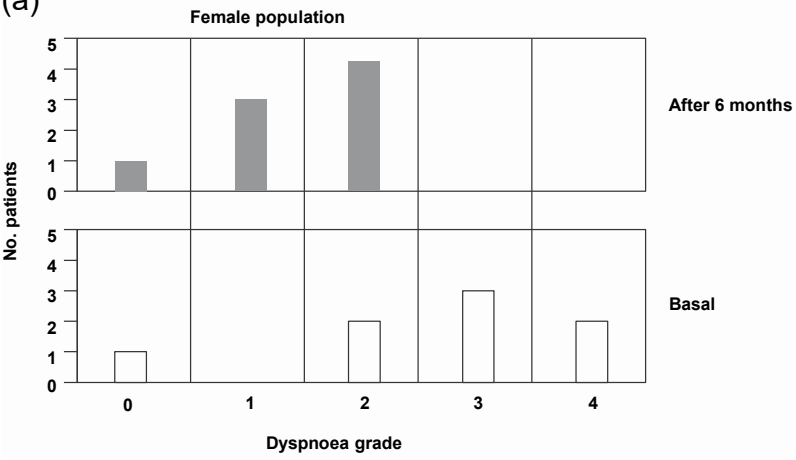

(b)

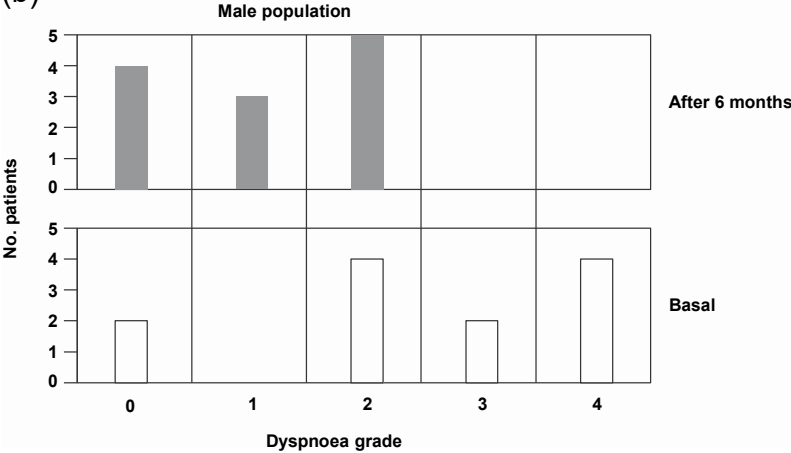

Figure 5 Dyspnoea grade at the end of a 6-min walking distance test is reported for (a) female and (b) male patients, before training with Respivol $^{\mathrm{TM}}$ (basal value) and after 6 months training. Grade $0=$ absent; $1=$ very-very low; $2=$ very low; $3=$ low; $4=$ moderate.

Table 2 A 6-min walking distance test

\begin{tabular}{lcc}
\hline & Basal $(\mathrm{m})$ & 6 months $(\mathrm{m})$ \\
\hline Male & $370 \pm 34$ & $455 \pm 42$ \\
Female & $280 \pm 25$ & $370 \pm 29$ \\
\hline
\end{tabular}

Respivol $^{\mathrm{TM}}$ use, compared with basal data. In this test the results obtained in women and men were also analysed separately. Both female and male patients showed a significant beneficial effect from Respivol ${ }^{\mathrm{TM}}$ use, as reported in Table 2.

\section{DISCUSSION}

Symptoms, such as the degree of dyspnoea and leg fatigue during exercise, are significant variables that influence the health-related $\mathrm{QoL}$ in patients with COPD. Recently, the beneficial effect of pulmonary rehabilitation on the improvement of dyspnoea symptom and leg fatigue has been demonstrated..$^{18}$ Pulmonary rehabilitation is based on increased fitness, on the prevention of muscle atrophy and the improvement of mobility. Home exercise programmes after hospitalisation for an exacerbation of
COPD has been recently shown to be useful to reduce the number of subsequent exacerbations. ${ }^{19}$ IMT is an exercise performed by COPD patients to improve their symptoms and QoL.

Recently a systematic review, performed to evaluate the effect of IMT in adults with COPD, has been published. ${ }^{20}$ The data reported in this review confirmed the effectiveness of IMT both in female and male patients and for patients with COPD, when threshold or targeted devices that control or provide a target for training intensity are used. The use of targeted inspiratory resistive or threshold modes of IMT has been shown to ensure that the training intensity is achieved and maintained during the exercise protocol, whereas non-targeted inspiratory resistive mode does not. ${ }^{20,21}$ Targeted resistive or threshold IMT has been found associated with significant improvements in PImax, endurance, exercise capacity and dyspnoea. ${ }^{21}$

When prescribing IMT for individuals with COPD, clinicians must consider the individual's comorbidities, motivation, level of dyspnoea and severity of disease. ${ }^{22}$ Clinicians should choose training parameters that will improve the strength and the endurance of the inspiratory muscles in association with the least amount of risk for the patient. ${ }^{23}$

Many clinical results suggest that IMT should be carried out for at least a total of $30 \mathrm{~min}$ daily, but it can be spread over more than one session per day. ${ }^{20}$ Training should occur at least 5 days per week. IMT should become part of the individual's routine exercise programme. The minimum training intensity necessary to obtain a training effect is less clear and may depend on the type of supervision provided. It could start as low as $22 \%$ PImax and be progressed to as high as $60 \%$ PImax, by using a targeted inspiratory resistive or threshold training. Finally, using threshold training, the intensity of effort is set on the device; so if a person does not generate a high enough pressure to achieve the load, the valve does not open and the person is unable to inspire. If resis-

tive training is used, the device provides a target that can be reached by the patient (or not) while still being able to inspire.

The efficacy of home IMT, performed by using a new exerciser (Respivol ${ }^{\mathrm{TM}}$ ), in improving the pulmonary symptoms in COPD patients is reported. The intensity level of IMT was improved with daily exercise with Respivol $^{\mathrm{TM}}$ in each patient, although the degree varied. The results support the use of Respivol $^{\mathrm{TM}}$ as part of a home training programme for COPD patients and support the importance of using devices that involve targets for training intensity.

\section{REFERENCES}

1 ACCP/AACVPR. Pulmonary Rehabilitation Guideline Panel. Pulmonary rehabilitation: joint ACCP/AACVPR evidence-based guidelines. Chest 1997; 112: 1363-96.

2 American Thoracic Society. Pulmonary Rehabilitation1999. Am. J. Respir. Crit. Care Med. 1999; 159: 1666-82.

3 Killian KJ, Jones NL. Respiratory muscles and dyspnea. Clin. Chest Med. 1988; 9: 237-48. 
4 Grosselink R, Troosters T, Decramer M. Peripheral muscle weakness contributes to exercise limitation in COPD. Am. J. Respir. Crit. Care Med. 1996; 153: 976-80.

5 Begin P, Grassino A. Inspiratory muscle dysfunction and chronic hypercapnia in chronic obstructive pulmonary disease. Am. Rev. Respir. Dis. 1991; 143: 905-12.

6 Black LF, Hyatt RE. Maximal respiratory pressures: normal values and relationship to age and sex. Am. Rev. Respir. Dis. 1969; 99: 696-702.

7 Kim MJ, Larson JL, Covey MK, Viatlo CA, Alex CG, Patel M. Inspiratory muscle training in patients with chronic obstructive pulmonary disease. Nurs. Res. 1993; 42: 35662 .

8 Larson JL, Kim MJ, Sharp JT, Larson DA. Inspiratory muscle training with a pressure threshold breathing device in patients with chronic obstructive pulmonary disease. Am. Rev. Respir. Dis. 1988; 138: 689-96.

9 Grosselink R, Wagenaar RC, Decramer M. The reliability of a commercially available threshold loading device. Thorax 1996; 51: 601-5.

10 Gething AD, Williams M, Davies B. Inspiratory resistive loading improves cycling capacity: a placebo controlled trial. Br. J. Sports Med. 2004; 38: 730-60.

11 Belman MJ, Shadmehr R. Targeted resistive ventilatory muscle training in chronic pulmonary disease. J. Appl. Physiol. 1988; 65: 2726-35.

12 Weiner P, Azgaad Y, Ganam R, Weiner M. Inspiratory muscle training in patients with bronchial asthma. Chest 1992; 102: 1357-61.

13 Hamilton N, Killian KJ, Summers E, Jones NL. Muscle strength, symptom intensity and exercise capacity in patients with cardiorespiratory disorders. Am. J. Respir. Crit. Care Med. 1995; 152: 2021-31.
14 Lisboa C, Munoz V, Beroiza T, Leiva A, Cruz E. Inspiratory muscle training in chronic airflow limitation: comparison of two different training loads with a threshold device. Eur. Respir. J. 1994; 7: 1266-74.

15 Smith K, Cook D, Guyatt GH, Madhavan J, Oxman AD. Respiratory muscle training in chronic airflow obstruction. Am. Rev. Respir. Dis. 1992; 145: 533-9.

16 National Institutes of Health. National Heart, Lung and Blood Institute. WHO Workshop, 1988. Global Initiative for Chronic Obstructive Lung Disease. Review 2004.

17 Camarri B, Eastwood PR, Cecins NM, Thompson PJ, Jenkins S. Six minute walk distance in healthy subjects aged 55-75 years. Respir. Med. 2006; 100: 658-65.

18 Katsura H, Yamad K, Wakaabayahi R, Kida K. The impact of dyspnoea and leg fatigue during exercise on healthrelated quality of life in patients with COPD. Respirology 2005; 10: 485-90.

19 Murphy N, Bell C, Costello RW. Extending a home from hospital care programme for COPD exacerbations to include pulmonary rehabilitation. Respir. Med. 2005; 99: 1297-302.

20 Geddes EL, Reid WD, Crowe J, O'Brien K, Brooks D. Inspiratory muscle training in adults with chronic obstructive pulmonary disease: a systematic review. Respir. Med. 2005; 99: 1440-58.

21 Reid WD, Sharma A. Respiratory muscle training in people with chronic obstructive pulmonary disease. Physiother. Singapore 2000; 3: 113-26.

22 Kennedy WL, ed. ACSM's Guidelines for Exercise Testing and Prescription. Williams and Wilkins, Media, PA, 1995.

23 Reid WD, Geddes EL, Brooks D, O’Brien K, Crowe J. Inspiratory muscle training in chronic obstructive pulmonary disease. Physiother. Can. 2004; 52: 128. 